OPEN ACCESS

Edited by:

Amit Kumar Tyagi,

University of Texas MD Anderson

Cancer Center, USA

Reviewed by:

Shinjini Singh,

University of Texas MD Anderson

Cancer Center, USA

Agnieszka Waśkiewicz,

Poznañ University of Life Sciences,

Poland

*Correspondence:

Venkataramana Mudil ramana.micro@gmail.com

Specialty section:

This article was submitted to

Food Microbiology,

a section of the journal

Frontiers in Microbiology

Received: 12 February 2016

Accepted: 26 May 2016

Published: 13 June 2016

Citation:

Sellamani M, Kalagatur NK Siddaiah C, Mudili V, Krishna K, Natarajan G and Rao Putcha VL (2016) Antifungal and Zearalenone Inhibitory Activity of Pediococcus pentosaceus Isolated from Dairy Products on Fusarium graminearum.

Front. Microbiol. 7:890. doi: 10.3389/fmicb.2016.00890

\section{Antifungal and Zearalenone Inhibitory Activity of Pediococcus pentosaceus Isolated from Dairy Products on Fusarium graminearum}

\author{
Muthulakshmi Sellamani ${ }^{1}$, Naveen K. Kalagatur ${ }^{2}$, Chandranayaka Siddaiah ${ }^{3}$, \\ Venkataramana Mudili' ${ }^{*}$, Kadirvelu Krishna ${ }^{1,4}$, Gopalan Natarajan ${ }^{5}$ and \\ Venkata L. Rao Putcha' ${ }^{1}$ \\ ${ }^{1}$ Toxicology and Immunology Division, DRDO-BU-Centre for Life sciences, Bharathiar University Campus, Coimbatore, India, \\ ${ }^{2}$ Food Microbiology Division, Defence Food Research Laboratory, Mysore, India, ${ }^{3}$ Department of Biotechnology, University \\ of Mysore, Mysore, India, ${ }^{4}$ Defence Bioengineering and Electromedical Laboratory, Bangalore, India, ${ }^{5}$ Food Biotechnology \\ Division, Defence Food Research Laboratory, Mysore, India
}

The present study was aimed to evaluate the bio-control efficacy of Pediococcus pentosaceus isolated from traditional fermented dairy products originated from India, against the growth and zearalenone (ZEA) production of Fusarium graminearum. The cell-free supernatants of $P$. pentosaceus (PPCS) were prepared and chemical profiling was carried out by GC-MS and MALDI-TOF analysis. Chemical profiling of PPCS evidenced that, the presence of phenolic antioxidants, which are responsible for the antifungal activity. Another hand, MALDI-TOF analysis also indicated the presence of antimicrobial peptides. To know the antioxidant potential of PPCS, DPPH free radical scavenging assay was carried out and $\mathrm{IC}_{50}$ value was determined as $32 \pm 1.89 \mu \mathrm{L} / \mathrm{mL}$. The antifungal activity of $P$. pentosaceus was determined by dual culture overlay technique and zone of inhibition was recorded as $47 \pm 2.81 \%$, and antifungal activity of PPCS on F. graminearum was determined by micro-well dilution and scanning electron microscopic techniques. The minimum inhibitory concentration (MIC) of PPCS was determined as $66 \pm 2.18 \mu \mathrm{L} / \mathrm{mL}$ in the present study. Also a clear variation in the micromorphology of mycelia treated with MIC value of PPCS compared to untreated control was documented. Further, the mechanism of growth inhibition was revealed by ergosterol analysis and determination of reactive oxygen species (ROS) in PPCS treated samples. The effects of PPCS on mycelial biomass and ZEA production were observed in a dose-dependent manner. The mechanism behind the suppression of ZEA production was studied by reverse transcriptase GPCR analysis of ZEA metabolic pathway genes (PKS4 and PKS13), and results showed that there is a dose dependent down-regulation of target gene expression in PPCS treated samples. The results of the present study were collectively proved that, the antifungal and ZEA inhibitory activity of PPCS against $F$. graminearum and it may find a potential application in agriculture and food industry as a natural bio-controlling agent.

Keywords: $F$. graminearum, Zearalenone, $P$. pentosaceus, minimum inhibitory concentration, dual culture overlay technique, ergosterol, reactive oxygen species, reverse transcriptase qPCR analysis 


\section{INTRODUCTION}

Mycotoxins are toxic secondary metabolites of filamentous fungi and predominantly produced by Aspergillus, Penicillium, and Fusarium species (Venkataramana et al., 2013, 2014; Priyanka et al., 2014). The fungal infestation of agricultural commodities usually occurs during pre and post-harvesting sessions as a result of improper handling, transportation and storage practices (Morgavi et al., 2007). The Food and Agriculture Organization (FAO) of the United Nations reported that about 25\% of agricultural products throughout worldwide were contaminated with fungi and mycotoxins (McKellar and Lu, 2003). The fungal infestation of agricultural commodities could result in the loss of grain texture, color, nutritional quality, and finally brings immense financial loss to the farming society (Morgavi et al., 2007). Consumption of mycotoxins contaminated food and feed could cause acute and chronic mycotoxicosis, including teratogenic, carcinogenic, oestrogenic, neurotoxic, and immunosuppressive effects (Morgavi et al., 2007; Venkataramana et al., 2015). Due to the deleterious effects of toxigenic fungi and their toxins present in the food grains and food products, it could be considered as a great threat to the society in terms of microbiological safety and food security (Pitt and Hocking, 2009).

Among the toxigenic fungal species, Fusarium graminearum was most considerable due to the high prevalence of different agro-climatic conditions with the ability to produce multiple mycotoxins, including zearalenone (ZEA), deoxynivalenol (DON), and nivalenol (NIV) (Morgavi et al., 2007; Ramana et al., 2011; Bernhoft et al., 2012; Venkataramana et al., 2014). The ZEA also known as an F-2 toxin and only reported non-steroidal estrogenic mycotoxin produced by F. graminearum in temperate climatic conditions (Zinedine et al., 2007). ZEA binds strongly with $17 \beta$-estradiol of cytosolic estrogen receptors present in the uterus and mammary gland and causes reproductive disorders such as the expansion of ovaries and uterus, vulvovaginitis and immature births in farm animals, and also occasionally responsible for hyperoestrogenism in humans (Minervini and Dell'Aquila, 2008). Recent reports on ZEA toxicity revealed that it could cause genotoxic (Gao et al., 2013), hepatotoxic (Stadnik and Borzecki, 2009), immunotoxic (Salah-Abbès et al., 2010), and neurotoxic effects (Venkataramana et al., 2014) in humans and animals. The international agency for research on cancer (IARC) also reported the carcinogenic properties of ZEA in laboratory animals and categorized as a Group 3 carcinogen (IARC, 1999). Keeping these toxicological aspects of ZEA, regulatory agencies throughout the worldwide proposed the maximum permissible limits in food and feed matrices. The joint FAO/WHO Expert Committee on Food Additives (JECFA) has suggested a Provisional Maximum Tolerable Daily Intake (PMTDI) of $0.5 \mu \mathrm{g} / \mathrm{kg}$ body weight (JECFA, 2000). The European Union (EU) has recognized permissible limits for ZEA in unprocessed cereals as $100 \mu \mathrm{g} / \mathrm{kg}$ excluding maize and in unprocessed maize was $350 \mu \mathrm{g} / \mathrm{kg}$ (European Commission, 2007). However, reports of Pleadin et al. (2012) revealed that maize grains were contaminated with high levels of $5.11 \mathrm{mg} / \mathrm{kg}$ ZEA and also Yoshinari et al. (2014) reported that Job's tears products of cereals have been found as 3.1 to $5.9 \mu \mathrm{g} / \mathrm{kg}$ of ZEA. These reports, further warns that there is an immediate need to develop a cost-effective bio-control strategy for successive mitigation of F. graminearum and ZEA contamination in food grains intended for consumption.

Currently, the use of synthetic antifungal agents for control of fungi is in practice. However, due to consumer safety and awareness, the use of chemical and synthetic fungicides is a great threat to the society due to increasing in multiple drug resistant microbes, environmental pollution and its residual toxicity to animals and humans (Kretschmer et al., 2009). Therefore, there is a trend to use bio-agents to control the fungal growth and the elimination of mycotoxins in food and feed commodities by several agricultural and food industries (Raut and Karuppayil, 2014). In this connection, several researchers were reported the use of microorganisms such as yeast, filamentous fungi and bacteria as antifungal agents (Dalie et al., 2010), and inhibitors of mycotoxin synthesis (Gourama and Bullerman, 1995; Gourama, 1997) as well as mycotoxin detoxifying agents (Fuchs et al., 2008; Wang et al., 2015). With this instance, Lactic acid bacteria (LAB) has been used as a safe bio-preservative agent for storing several food products through globally. LAB was declared as GRAS (generally recognized as safe) by FDA (Food and Drug Administration) and also as QPS (qualified presumption of safety) status by EFSA (European Food Safety Authority). LAB plays a major role in the preservation of fermented food products by maintaining the microbial stability through their antimicrobial active metabolites such as organic acids (mainly lactic acid and acetic acid), reuterin, phenyllactic acid, fatty acids, and bacteriocins (Dalie et al., 2010). LAB also exhibited potential features such as antifungal, inhibitors of mycotoxin synthesis, and mycotoxin detoxifying agents, which are much required in agricultural and food sector. Gourama and Bullerman (1995) reported the antifungal and anti-aflatoxin production properties of lactic acid and other active metabolites of LAB. Lavermicocca et al. (2000) also reported the antifungal activity of phenyllactic acid and 4-hydroxyl-phenyl-lactic acid isolated from Lactobacillus plantarum. Similarly, Dalie et al. (2010), observed the inhibition of growth and fumonisins production of $F$. proliferatum and $F$. verticillioides by $P$. pentosaceus (L006) isolated from maize leaf. Recently Wang et al. (2015) reported that $\mathrm{LAB}$ strains possess the detoxification property of mycotoxins through binding mechanism to the bacterial cell wall components such as polysaccharides and proteins. In addition to this, Peltonen et al. (2001) reported the binding properties of dairy strains toward aflatoxin B1 and also Fuchs et al. (2008) reported the detoxification of patulin and ochratoxin A in aqueous solution by L. acidophilus VM 20 and B. animalis VM 12.

Owing to the above, the present study was aimed to evaluate the inhibitory activity of $P$. pentosaceus culture supernatant (PPCS) on the growth and ZEA production of F. graminearum. The chemical profiling of PPCS was carried out by MALDITOF and GC-MS methods. Antioxidant activity of PPCS was determined by DPPH free radical scavenging assay and antifungal activity was determined by micro-well dilution, welldiffusion and scanning electron microscopic (SEM) methods. 
The mechanism of growth inhibitory activity of PPCS on F. graminearum was revealed by determining the ergosterol content and reactive oxygen species (ROS) production. The ZEA synthesis inhibitory activity of PPCS at genetic level was determined by the reverse transcriptase qPCR (Rt-qPCR) method as well as UHPLC analysis of ZEA.

\section{MATERIALS AND METHODS}

\section{Chemicals and Media}

Potato dextrose (PD) agar and broth, Czapek-Dox (CD) agar and broth, de Man, Rogosa and Sharpe (MRS) agar and broth, malt extract soft (MES) agar, peptone and 2,2-diphenyl-1picrylhydrazyl (DPPH) were obtained from HiMedia, (Mumbai, India). Dichloro-dihydro-fluorescein diacetate (DCFH-DA), $\alpha$-cyano-4-hydroxy cinnamic acid, trifluoroacetic acid (TFA), methanol, ergosterol and zearalenone (ZEA) were obtained from Sigma-Aldrich (Bangalore, India). All the plasticware used in the study were acquired from Eppendorf (Bangalore, India), and other chemicals and solvents used in the study were fine grade and acquired from Merck Millipore (Bangalore, India).

\section{Screening and Isolation of Lactic Acid Bacteria}

The dairy products including paneer, khoa, peda, kulfi, ghee, kheer, and yogurt were collected from local markets of Coimbatore (Tamil Nadu, India) and used for isolation LAB. A $10 \mathrm{mg}$ of samples were homogenized with $9 \mathrm{~mL}$ of sterile distilled water containing $0.85 \% \mathrm{NaCl}$ and $0.1 \%$ peptone. A 10 fold serial dilutions were made from $10^{-1}$ to $10^{-7}$ and spread plated on MRS agar and incubated at $37^{\circ} \mathrm{C}$ for $48 \mathrm{~h}$ under aerobic condition. The colonies were picked randomly and streaked plated on MRS agar and incubated for $48 \mathrm{hrs}$ at $37^{\circ} \mathrm{C}$. The pure colonies were grown in MRS broth and stored at $4^{\circ} \mathrm{C}$ for further studies.

\section{Molecular Identification of LAB}

The genomic DNA was extracted from the overnight grown culture of LAB using genomic DNA extraction kit (Roche life science, USA) following the instructions of the manufacturer. The PCR was set for extracted DNA using 16S rRNA universal primers (Table 1) and briefly, $20 \mu \mathrm{L}$ volume of reaction mixture

TABLE 1 | Primer sequences were used in the present study.

\begin{tabular}{lcc}
\hline Target Gene & Primer sequence $\left(\mathbf{5}^{\prime}\right.$ to $\left.\mathbf{3}^{\prime}\right)$ & $\mathbf{T m}\left({ }^{\circ} \mathbf{C}\right)$ \\
\hline GAPDH-F & TATCACGTCTGCCACGAT & 56 \\
GAPDH-R & CATGTAGGCCTGTGATGA & \\
PKS13-F & TACCCGCCTCGTTAAG & 56 \\
PKS13-R & AGCTGGCTAAGCGAGGCA & \\
PKS4-F & ATCGGTCATCTTGAGGCT & 58 \\
PKS4-R & CCGTAGAGAATGCTTGT & \\
$27 F$ & AGAGTTGATCM (A/C) TGGCTCAG & 56 \\
$1492 \mathrm{R}$ & TACCTTGTTACGACTT &
\end{tabular}

included: $2 \mu \mathrm{L}$ of PCR reaction buffer (10X), $0.2 \mu \mathrm{L}$ of Taq polymerase ( 1 unit/ $1 \mu \mathrm{L}), 1 \mu \mathrm{L}$ of $16 \mathrm{~S}$ rRNA primers $(500 \mathrm{nM})$, $1 \mu \mathrm{L}$ of template DNA (100 ng) and $15.8 \mu \mathrm{L}$ of nucleasefree water (PCR grade). The PCR reaction was carried out in Mastercycler nexus (Eppendorf, Germany) with following conditions: initial denaturation at $94^{\circ} \mathrm{C}$ for $3 \mathrm{~min}$, denaturation at $94^{\circ} \mathrm{C}(45 \mathrm{~s})$, annealing at $55^{\circ} \mathrm{C}(1 \mathrm{~min})$, elongation at $72^{\circ} \mathrm{C}$ for $2 \mathrm{~min}$ and final extension at $72^{\circ} \mathrm{C}$ for $10 \mathrm{~min}$ up to 35 cycles. The PCR product was purified using High Pure PCR Product Purification Kit following the instructions of the manufacturer (Roche life science, USA) and sequenced at Eurofins Genomics India Pvt Ltd (Bangalore, India). The molecular identification of LAB strains was determined using BLAST analysis.

\section{Characterization of $P$. pentosaceus Culture Supernatant (PPCS)}

Pediococcus pentosaceus was grown in $100 \mathrm{~mL}$ of MRS broth in $250 \mathrm{~mL}$ Erlenmeyer flask at $37^{\circ} \mathrm{C}$ for $48 \mathrm{~h}$ under aerobic condition. The cell-free supernatant was collected by centrifugation ( $8000 \mathrm{rpm}$ for $10 \mathrm{~min}$ at $4^{\circ} \mathrm{C}$ ) and filtered through a sterile filter $(0.22 \mu \mathrm{m}$, Millipore) and referred as PPCS. The PPCS was concentrated by ammonium sulfate precipitation method and the precipitate was dialyzed against $0.5 \mathrm{mM}$ phosphate buffered saline $\mathrm{pH} 7.4$ (PBS) for $72 \mathrm{~h}$ with four buffer changes in order to remove the salts and stored at $-20^{\circ} \mathrm{C}$ for further use.

\section{GC-MS Analysis}

The chemical profiling of PPCS was carried out by gas chromatography-mass spectrometry (GC-MS) analysis on PerkinElmer Clarus $600^{\circ} \mathrm{C}$ equipped with DB-5MS (30 m $\times 0.25 \mathrm{~mm} ; 0.25 \mu \mathrm{m}$ film thickness) combined silica capillary column and flame-ionization detector (FID). The PPCS was diluted with ethyl acetate $(10 \mu \mathrm{L} / \mathrm{mL})$ and $1 \mu \mathrm{L}$ solution was used for analysis in split-mode of 1:30. Helium was the carrier gas with a flow of $1 \mathrm{~mL} / \mathrm{min}$, and temperature for injector and sensor were set at $250^{\circ} \mathrm{C}$ and $280^{\circ} \mathrm{C}$, respectively. The column temperature was linearly programmed from 40 to $280^{\circ} \mathrm{C}$ at $4^{\circ} \mathrm{C} / \mathrm{min}$ and documentation of mass spectra was recorded in EI mode $(70 \mathrm{eV})$ with a range of $\mathrm{m} / \mathrm{z} 40-450 \mathrm{amu}$. The Turbo Mass software application was adopted to operate and acquire data from GC-MS. The individual components of PPCS were determined based on the MS spectra of accessible reference libraries (NIST/Wiley). The concentration (\%) of constituent components were obtained from GC peak area with devoid of FID response factor.

\section{MALDI-TOF Analysis}

The Matrix Assisted Laser Desorption/Ionization Time-Of-Flight (MALDI-TOF) spectrum of PPCS dialysate was acquired on an Ultra flex Bruker mass spectrometer (Billerica, MA, USA). An analyte was prepared by mixing equal amounts of PPCS with saturated $0.1 \%$ TFA and methanol (1:1), and injected into 100well stainless steel by dried drop method. The analysis was carried out in a linear positive mode with a nitrogen laser at $337 \mathrm{~nm}$ and $15 \mathrm{kV}$. The analysis was carried in multiple times to obtain clear spectra and measured masses have an error of $\sim \pm 3 \mathrm{Da}$. 


\section{Antioxidant Activity}

The DPPH free radical scavenging activity of PPCS was determined following the methodology of Kalagatur et al. (2015) with minor modifications. A volume of $1 \mathrm{~mL}$ of acetate buffer, $1 \mathrm{~mL}$ of ethanol and $0.5 \mathrm{~mL}$ of $0.25 \mathrm{mM}$ DPPH solution were added to the different volumes of PPCS and incubated under dark at room temperature for $30 \mathrm{~min}$. The solution mixture without test sample and with quercetin was referred as control and standard, respectively. Following the incubation period, the absorbance was recorded at $517 \mathrm{~nm}$ using multimode plate reader (Bioteck Synergy H1, USA). The result was stated as $\mathrm{IC}_{50}$ $(\mu \mathrm{L} / \mathrm{mL})$, which represents the quantity of PPCS required to reduce the absorbance of DPPH by $50 \%$. The DPPH free radical scavenging activity of PPCS was calculated by the formula,

$\mathrm{DPPH}$ radial scavenging activity $(\%)=[(\mathrm{Ac}-\mathrm{At}) / \mathrm{Ac}] \times 100$

Where, Ac was the absorbance of the control and At was the absorbance of the test sample (PPCS or standard).

\section{Antifungal Activity}

Fusarium graminearum (MTCC 1893) positive for ZEA biosynthesis was obtained from the Microbial Type Culture Collection Center and Gene Bank (MTCC), Chandigarh, India, and grown on $\mathrm{CD}$ agar for 7 days at $28^{\circ} \mathrm{C}$ and spores were recovered using peptone water containing $0.001 \%$ Tween 80 with a soft scrape. The spore number was estimated using haemocytometer and spore number was adjusted to $1 \times 10^{6}$ per $\mathrm{mL}$. The antifungal activity of $P$. pentosaceus was determined by dual culture overlay technique in terms of zone of inhibition. The antifungal activity of PPCS was determined by micro-well dilution and scanning electronic microscopic methods and also the mechanism of antifungal activity was determined by estimating ergosterol and ROS.

\section{Dual Culture Overlay Technique}

Antifungal activity of $P$. pentosaceus was determined by dual culture overlay technique following the methodology of Magnusson and Schnürer (2001) with minor modifications. A two $\mathrm{cm}$ line of $P$. pentosaceus was streaked on MRS agar plates and incubated for $48 \mathrm{~h}$ at $28^{\circ} \mathrm{C}$ under aerobic condition. Following the incubation period, the plates were overlaid with MES agar and inoculated with $10 \mu \mathrm{L}$ fungal spore suspension $\left(1 \times 10^{6}\right.$ spores $\left./ \mathrm{mL}\right)$ and further incubated for 7 days at $28^{\circ} \mathrm{C}$. The zone of growth inhibition was measured in $\mathrm{mm}$ using Zonescale (HiMedia, Mumbai, India).

\section{Micro-Well Dilution}

The antifungal activity of PPCS was determined in terms of minimum inhibitory concentration (MIC) by micro-well dilution technique in 96 well microtiter plates following the methodology of CLSI and Kalagatur et al. (2015) with minor modifications. A volume of $10 \mu \mathrm{L}$ fungal spore suspension $\left(1 \times 10^{6}\right.$ spores $\left./ \mathrm{mL}\right)$ was added to the different volumes of PPCS and final volume was adjusted to $200 \mu \mathrm{L}$ with CD broth. The wells with $0.001 \%$ Tween 80 and $10 \mu \mathrm{L}$ spore suspension $\left(1 \times 10^{6}\right.$ spores $\left./ \mathrm{mL}\right)$ were referred as control and neomycin were used as a standard. The plate was incubated for 3 days at $28^{\circ} \mathrm{C}$ and optical density was recorded at $620 \mathrm{~nm}$ using multimode plate reader (Synergy H1, BioTek, USA). The minimum concentration at which absolutely inhibited fungal growth was determined as MIC value. The inhibition of fungal growth was calculated by the formula,

$$
\text { Growth inhibition }(\%)=\text { At } / \text { Ac } \times 100
$$

Where, Ac and At are absorbance of control and test sample (PPCS or standard), respectively.

\section{Scanning Electron Microscopic Observation}

The antifungal activity of PPCS on the mycelial structure of F. graminearum was determined by SEM observation following the methodology of Kalagatur et al. (2015) with minor modifications. A 3 days old culture of F. graminearum grown on $\mathrm{CD}$ agar was treated with an $\mathrm{IC}_{50}$ value of PPCS and incubated at $28^{\circ} \mathrm{C}$ for $24 \mathrm{~h}$. Subsequently, the mycelia were washed for twice with PBS and attached to dual adhesive carbon tape and subjected to drying under $\mathrm{CO}_{2}$. The mycelia were sputter coated with gold and the morphological feature was observed under SEM (FEI, USA) at 20.0 KV in environmental mode. The mycelia without PPCS treated was referred as a control.

\section{Determination of Ergosterol}

The determination of ergosterol content in F. graminearum was carried out following the methodology of Silva et al. (2010) with slight modifications. A volume of $10 \mu \mathrm{L}$ spore suspension $\left(1 \times 10^{6}\right.$ spores $\left./ \mathrm{mL}\right)$ and different volumes of PPCS were added to $100 \mathrm{~mL}$ of CD broth in Erlenmeyer flask and incubated at $28^{\circ} \mathrm{C}$ at $160 \mathrm{rpm}$ for a time period of 7 days. The flask alone with fungal spore suspension in $\mathrm{CD}$ broth was referred as a control. Following the incubation period, a $50 \mathrm{mg}$ of mycelia was blended with $5 \mathrm{~mL}$ of methanol, $1 \mathrm{~mL}$ of ethanol and $0.5 \mathrm{~g}$ of potassium hydroxide under $250 \mathrm{rpm}$ for $20 \mathrm{~min}$ and incubated for $40 \mathrm{~min}$ in water bath at $70^{\circ} \mathrm{C}$. The supernatant was recovered by centrifugation (8000 rpm for $10 \mathrm{~min}$ ) and blended with an equal volume of $\mathrm{n}$-hexane for $2 \mathrm{~min}$ at $8000 \mathrm{rpm}$ and incubated for $10 \mathrm{~min}$ at room temperature. The mixture was completely dried over a water bath at $60^{\circ} \mathrm{C}$ and dissolved in $1 \mathrm{~mL}$ of methanol. The optical density was measured at excitation and emission wavelength of $240 \mathrm{~nm}$ and $300 \mathrm{~nm}$, respectively, using UV-3600 spectrophotometer (Shimadzhu, Japan). The quantification of ergosterol content was carried out in Nexera UHPLC (Shimadzu, Kyoto, Japan) equipped with the C18 column, $5 \mu \mathrm{m}, 250 \mathrm{~mm} \times 4.60 \mathrm{~mm}$ (Phenomenex, USA). The analysis was carried with following conditions: mobile phase was acetonitrile and water $(6.5: 3.5, \mathrm{v} / \mathrm{v})$, injection volume was $25 \mu \mathrm{L}$ and UV detector was used with excitation and emission wavelengths of $240 \mathrm{~nm}$ and $300 \mathrm{~nm}$, respectively. The concentration of ergosterol was determined from the standard calibration curve of ergosterol.

\section{Determination of ROS}

Effect of PPCS on the generation of ROS in F. graminearum was carried out in 96 well microtiter plates following the methodology of Kalagatur et al. (2016). A volume of $10 \mu \mathrm{L}$ fungal spore suspension $\left(1 \times 10^{6}\right.$ spores $\left./ \mathrm{mL}\right)$ was added to the different volumes of PPCS and final volume was adjusted to $200 \mu \mathrm{L}$ with 
$\mathrm{CD}$ broth, incubated at $28^{\circ} \mathrm{C}$ for 3 days. The wells with $0.001 \%$ Tween $80,10 \mu \mathrm{L}$ spore suspension $\left(1 \times 10^{6}\right.$ spores $\left./ \mathrm{mL}\right)$ and neomycin were referred as control and standard, respectively. After incubation, $5 \mu \mathrm{M}$ of DCFH-DA was added to wells and incubated for $20 \mathrm{~min}$ in the dark and absorbance was measured at excitation and emission wavelength of $495 \mathrm{~nm}$ and $550 \mathrm{~nm}$, respectively, in a multimode plate reader (Synergy H1, BioTek, USA). ROS was determined as percentage release with respect to the carrier $(0.001 \%$ Tween 80$)$ treated control. The images were captured using fluorescence microscope EVOS (Life Technologies, USA) at an excitation wavelength of $495 \mathrm{~nm}$ and an emission wavelength of $550 \mathrm{~nm}$.

\section{Antimycotoxic Activity of PPCS}

A volume of $10 \mu \mathrm{L}$ fungal spore suspension $\left(1 \times 10^{6}\right.$ spores $\left./ \mathrm{mL}\right)$ and different volumes of PPCS $(20,40$, and $66 \mu \mathrm{L} / \mathrm{mL})$ were added to the $100 \mathrm{~mL}$ of CD broth in $250 \mathrm{~mL}$ Erlenmeyer flask. The flask with fungal spore suspension and $100 \mathrm{~mL}$ of CD broth was considered as control. The flasks were incubated at $28^{\circ} \mathrm{C}$ for 14 days and broth culture was separated out from mycelia using Whatman no.1 filter paper. The ZEA concentration in broth culture was determined using UHPLC (Shimadzu, Kyoto, Japan) system equipped with fluorescent detector.

\section{Determination of Mycelial Biomass}

The mycelia were washed twice with PBS and collected in preweighed Whatman no. 1 paper and dried for $24 \mathrm{~h}$ at $60^{\circ} \mathrm{C}$. The dry weighed of mycelia biomass was determined using Denver instruments (Bangalore, India).

\section{Determination of ZEA}

The determination of ZEA in broth culture was carried out following our previous established methodology (Kalagatur et al., 2015). The selective extraction of ZEA was carried out using ZEA specific immunoaffinity column obtained from Vicam, USA. The column was pre-conditioned with PBS for $10 \mathrm{~min}$ and used for ZEA analysis. The broth was blended with an equal amount of acetonitrile for a period of $30 \mathrm{~min}$, and centrifuged for $12 \mathrm{~min}$ at $6000 \mathrm{rpm}$ and a volume of $15 \mathrm{~mL}$ supernatant was passed through ZEA immunoaffinity column. The column was washed with $5 \mathrm{~mL}$ of PBS and repeated with $10 \mathrm{~mL}$ distilled water and dried out. The ZEA was eluted with $5 \mathrm{~mL}$ of acetonitrile by maintaining contact between column antibodies for $5 \mathrm{~min}$. The eluant was dried over a water bath at $60^{\circ} \mathrm{C}$ and extract was redissolved in $1 \mathrm{~mL}$ of acetonitrile and filtered through $0.22 \mu \mathrm{m}$ filter, and used for the quantification of ZEA. The quantification of ZEA was carried out in Nexera UHPLC (Shimadzu, Kyoto, Japan) equipped with the C18 column, $5 \mu \mathrm{m}, 250 \mathrm{~mm} \times 4.60 \mathrm{~mm}$ (Phenomenex, USA). The analysis was carried out in reverse phase with following conditions: mobile phase was acetonitrile and water $(6: 4, \mathrm{v} / \mathrm{v})$ with flow rate of $1 \mathrm{~mL} / \mathrm{min}$, injection volume was $25 \mu \mathrm{L}$ and fluorescence detector was used with excitation and emission wavelengths of $334 \mathrm{~nm}$ and $450 \mathrm{~nm}$, respectively. A calibration curve for standard ZEA (100 ng - $5 \mu \mathrm{g} / \mathrm{mL}$ ) was constructed and used for determination of ZEA in test samples.

\section{Reverse Transcriptase qPCR (Rt-qPCR) Analysis of ZEA Metabolic Pathway Genes}

The PKS4 and PKS13 genes are involved in ZEA biosynthesis in F. graminearum (Kim et al., 2005; Gaffoor and Trail, 2006). The effect of PPCS on gene expression of PKS4 and PKS13 were analyzed by Rt-qPCR method. The fresh mycelia were flashfrozen with liquid nitrogen and ground into fine powder, and total RNA was extracted using RNA easy plant mini kit following the guidelines of the manufacturer (Qiagen, USA). The total RNA was quantified using NanoDrop 8000 Spectrophotometer (Thermo Scientific, USA) and stored at $-20^{\circ} \mathrm{C}$. The primers used for the target genes (PKS4, PKS13, and GAPDH) amplification (Table 1) were followed as per our previous report (Kalagatur et al., 2015). The Rt-qPCR analysis was carried in the Light cycler 480 (Roche, USA) using iScript One-Step RT-PCR Kit with SYBR Green master mix (BIO-RAD, Bangalore, India). In brief, $50 \mu \mathrm{L}$ volume of reaction mixture consists of $25 \mu \mathrm{L}$ of $2 \mathrm{X}$ SYBR Green master mix, $1 \mu \mathrm{L}$ of iScript reverse transcriptase, $1 \mu \mathrm{L}$ of primer $(450 \mathrm{nM}), 1 \mu \mathrm{L}$ of template RNA (100 ng) and $22 \mu \mathrm{L}$ of nuclease free water (PCR grade). The reaction conditions were as follows: $10 \mathrm{~min}$ of cDNA synthesis at $50^{\circ} \mathrm{C}$ for 1cycle, $5 \mathrm{~min}$ of polymerase activation at $95^{\circ} \mathrm{C}$ and followed by 35 cycles of PCR at $95^{\circ} \mathrm{C}$ for $10 \mathrm{~s}, 60^{\circ} \mathrm{C}$ for $30 \mathrm{~s}$ for combined annealing and extension. The relative quantitative expression of each gene was obtained from a second derivative maximum analysis by determination of the crossing point value normalized to the crossing points values of reference gene GAPDH. Data were shown as normalized ratios of genes together with a standard error by means of Roche Applied Science E-Method (Tellmann and Geulen, 2006).

\section{Statistical Analysis}

In the present study, all the experiments were carried out independently in six times and data were processed by one-way

TABLE 2 | Chemical characterization of Pediococcus pentosaceus culture supernatant (PPCS) by GC-MS analysis.

\begin{tabular}{lccc}
\hline S. No & Retention time & Compound & Composition (\%) \\
\hline 1 & 10.26 & D-Pro & 3.05 \\
2 & 10.47 & L-Pro & 2.91 \\
3 & 12.09 & Benzeneacetic acid & 12.46 \\
4 & 12.84 & Catechol & 1.79 \\
5 & 14.91 & Phenylpropanoic acid & 6.90 \\
6 & 17.58 & Salicylic acid & 8.14 \\
7 & 19.90 & Palmitic acid & 3.16 \\
8 & 20.94 & 3-Phenyllactic acid & 21.08 \\
9 & 21.88 & 4-Hydroxybenzoic acid & 4.91 \\
10 & 23.49 & Oleic acid & 2.60 \\
11 & 24.05 & 3-(3-Hydroxyphenyl) propionic acid & 1.15 \\
12 & 25.81 & 3-Hydroxydecanoic acid & 5.71 \\
13 & 27.01 & Hydroferulic acid & 3.59 \\
14 & 34.08 & trans-Caffeic acid & 4.27 \\
\hline & & Total & 81.72 \\
\hline
\end{tabular}




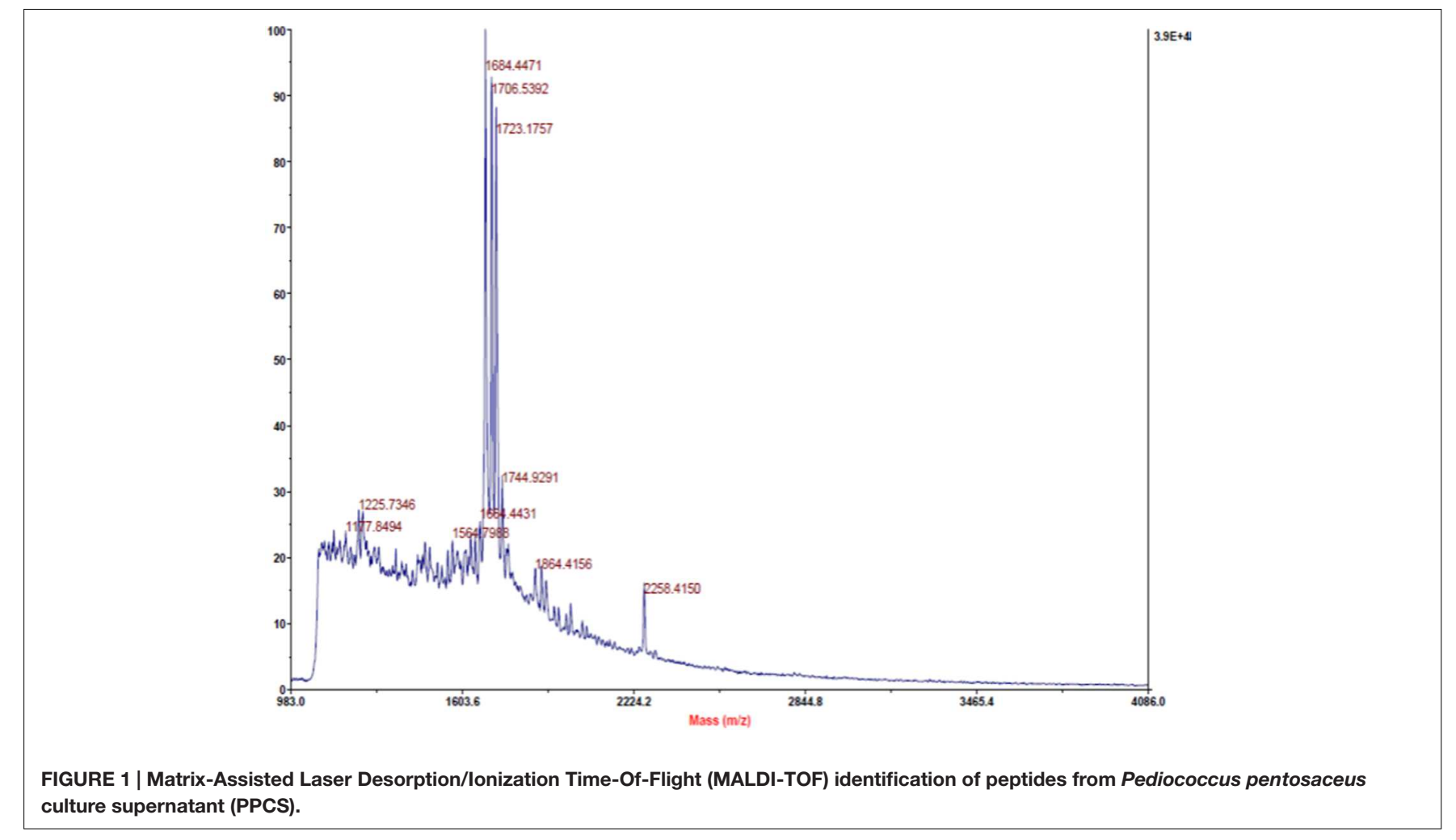

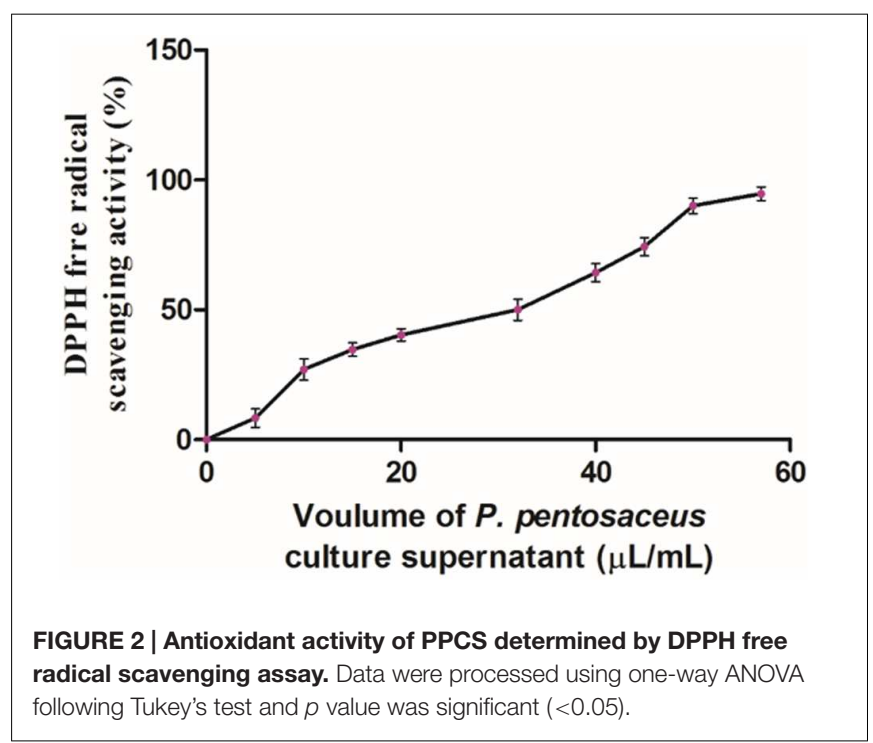

ANOVA following the Tukey's test. The result was considered significant at $p<0.05$ and represented as means \pm SD.

\section{RESULT AND DISCUSSION}

\section{Molecular Identification of LAB}

Isolation of LAB was carried out using selective agar medium (MRS) and pure colonies were isolated by streak plated technique
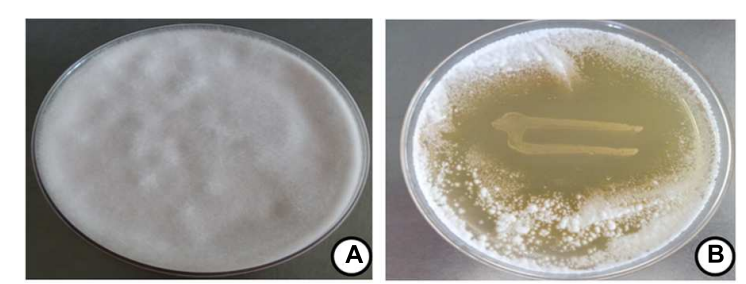

FIGURE 3 | Antifungal activity of $\boldsymbol{P}$. pentosaceus on $\boldsymbol{F}$. graminearum determined by dual culture overlay technique. Data were processed using one-way ANOVA following Tukey's test and $p$ value was significant $(<0.05)$. Fungal growth at (A) control and (B) P. pentosaceus streaked plate.

and stored at $4{ }^{\circ} \mathrm{C}$ for further use. To know the molecular identity of the isolated LAB culture $16 \mathrm{~S}$ rRNA sequencing was carried out and sequence was submitted to NCBI. BLAST analysis of $16 \mathrm{~S}$ rRNA revealed that, the isolated LAB was $P$. pentosaceus and obtained sequence was identified with NCBI accession number: SUB1500777 Pediococcus KX214298.

\section{Preparation and Profiling of PPCS}

Pediococcus pentosaceus cell-free supernatants were prepared and concentrated by ammonium sulfate based precipitation method as reported elsewhere. The chemical profile of PPCS was determined by GC-MS and MALDI-TOF analysis.

\section{GC-MS Analysis}

Chemical profile of PPCS was carried out by GC-MS analysis and results of the present study revealed that, there was a 


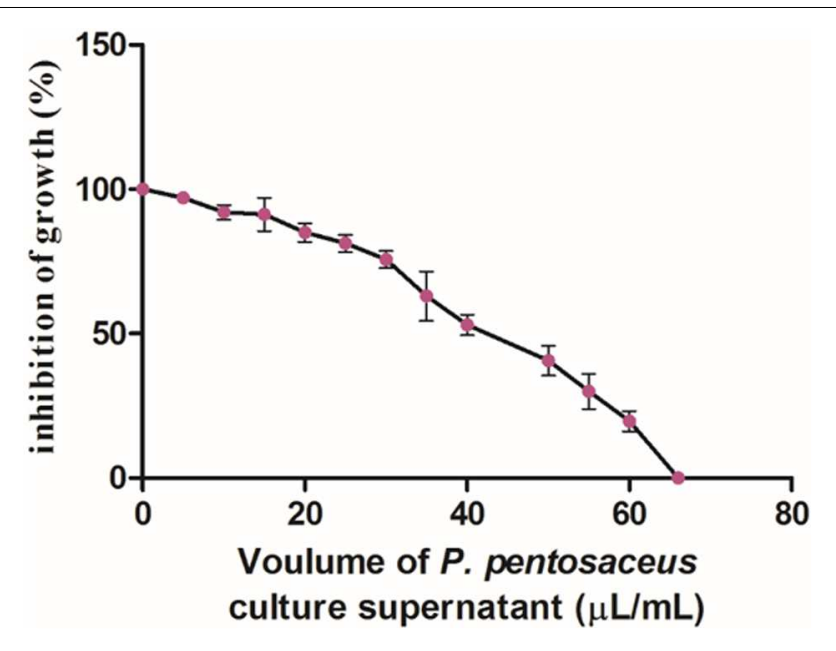

FIGURE 4 | Dose-dependet antifungal activity of PPCS determined by micro-well dilution method. Data were processed using one-way ANOVA following Tukey's test and $p$ value was significant $(<0.05)$.

presence of several antioxidants including phenylpropanoic acid, 3-phenyllactic acid, 3-hydroxydecanoic acid, hydroferulic acid, trans-caffeic acid, catechol, benzeneacetic acid, 4-hydroxybenzoic acid, 3-(3-hydroxyphenyl) propionic acid, and cyclic dipeptides including $\mathrm{D}$ and L- pro (Table 2). These results are in line with the earlier report of Mozzi et al. (2010). In the present study identified phenolic compounds in PPCS could be responsible for the determined antifungal activity. Also, these results are strongly supported by the reports of Dalie et al. (2010), for the antagonistic activity of PPCS against $F$. proliferatum and F. verticillioides. The antifungal activity of PPCS in the present study may be due to the presence of phenyllactic acid, 2-hydroxy-4-methylpentanoic acid, reuterin, benzoic acid, and lactic acid (Lavermicocca et al., 2003; Ndagano et al., 2011).

\section{MALDI-TOF Analysis}

In the present study, MALDI-TOF analysis of PPCS was carried out to know the presence of antimicrobial peptides. Study results revealed that there was the presence of three major peptides with a molecular mass of 1684.44, 1706.53, and 1723.17 (Figure 1). These results are in line with the earlier reports of (Singh et al., 2014), who reported the presence of a non-pediocin like peptide with a potent antimicrobial activity. In addition to this, we also identified other two uncharacterized peptides and presence of these peptides in PPCS might be the possible cause of determined antifungal activity in the present study. However, structural and functional characterization of these peptides is needed in detail to understand the mechanism of antifungal activity and role of PPCS.

\section{Antioxidant Activity}

$\mathrm{DPPH}$ assay is one of the reliable and sensitive methods for determination of antioxidant potential. The DPPH free radical gets scavenged by hydrogen donating electron group of antioxidant and the value was measured in $\mathrm{IC}_{50}$, which means the amount of antioxidant required to scavenge $50 \%$ of DPPH free radicals (Bondet et al., 1997). In the Present study, antioxidant potential of PPCS was carried out by DPPH free radical scavenging assay. Results of the present study showed that, the antioxidant potential of PPCS was dose-dependent in a manner (Figure 2) and the $\mathrm{IC}_{50}$ value was determined as $32 \pm 1.89 \mu \mathrm{L} / \mathrm{mL}$. In the present study, obtained result was in accordance with the previous reports of Balakrishnan and Agrawal (2014) who reported the enhancement of antioxidant potential (\%) of cow milk, goat milk and camel milk fermented with $P$. pentosaceus as $38.7 \pm 1.53$ to $78.0 \pm 0.74,54.0 \pm 1.02$ to $92.7 \pm 1.53$, and $64.4 \pm 01.42$ to $84.3 \pm 2.09$, respectively. The determined antioxidant activity may due to the presence of phenolic compounds and other secondary metabolites (Okcu et al., 2016) or antimicrobial peptides (Nishino et al., 2000).

\section{Antifungal Activity}

The antifungal property of $P$. pentosaceus cells was determined by dual culture overlay technique and zone of inhibition was observed as $47 \pm 2.81 \%$ (Figure 3). The observed results were in line previous report of Magnusson et al. (2003), who observed the potent antifungal activity of $P$. pentosaceus, L. acidophilus and L. plantarum against A. fumigatus J9, A. nidulans J283 (FSGC A4 wt), F. sporotrichioides J304 (ITEM168), P. commune J238 (IBT 12400), and $P$. roqueforti J268 (IBT 6754). In another study, Laitila et al. (2002) reported that, the antifungal activity of L. plantarum E76 and L. plantarum E98 on F. graminearum as $49 \pm 8$ and $50 \pm 5$, respectively. However, till date there is no such reports are available on antifungal activity of $P$. pentosaceus on F. graminearum.

In the present study, the antifungal activity of PPCS was determined by micro-well dilution method and results clearly revealed that there was dose-dependent decrease in growth of F. graminearum (Figure 4). The MIC value of PPCS against F. graminearum was determined as $66 \pm 2.18 \mu \mathrm{L} / \mathrm{mL}$ in broth culture and these results are in line with the antifungal activity of $P$. pentosaceus studied by dual culture overlay technique. Moreover, results of the present study was in accordance with the previous report of Ndagano et al. (2011), who reported the antifungal activity of LAB culture supernatants on A. nigerCWBIF194, A. nigerMUCL 28699, A. tubingensis MP1, and $P$. crustosumMY1.

The observed antifungal activity of PPCS was further validated by using SEM analysis to check the mycelial micro-morphological alterations in PPCS treated F. graminearum. The mycelia treated with determined MIC value of PPCS was used for SEM analysis. The SEM observation of F. graminearum was clearly evidenced that, control mycelia were showed healthy morphology with smooth, turgid, homogenous surface without any apparent change (Figure 5A). On the other hand, the morphology of PPCS treated mycelia were observed with notable changes in mycelia including shrinkage, wrinkle, disturbance, collapse, squash, non-homologous surface, and vesicles (Figure 5B). Moreover, the conidia treated with PPCS (Figure 5D) also exhibited irregular surface, shrinkage, craters and protuberance in structure compared to control (Figure 5C). These results are in line with the earlier reports of Zhao et al. (2014) and Kalagatur 

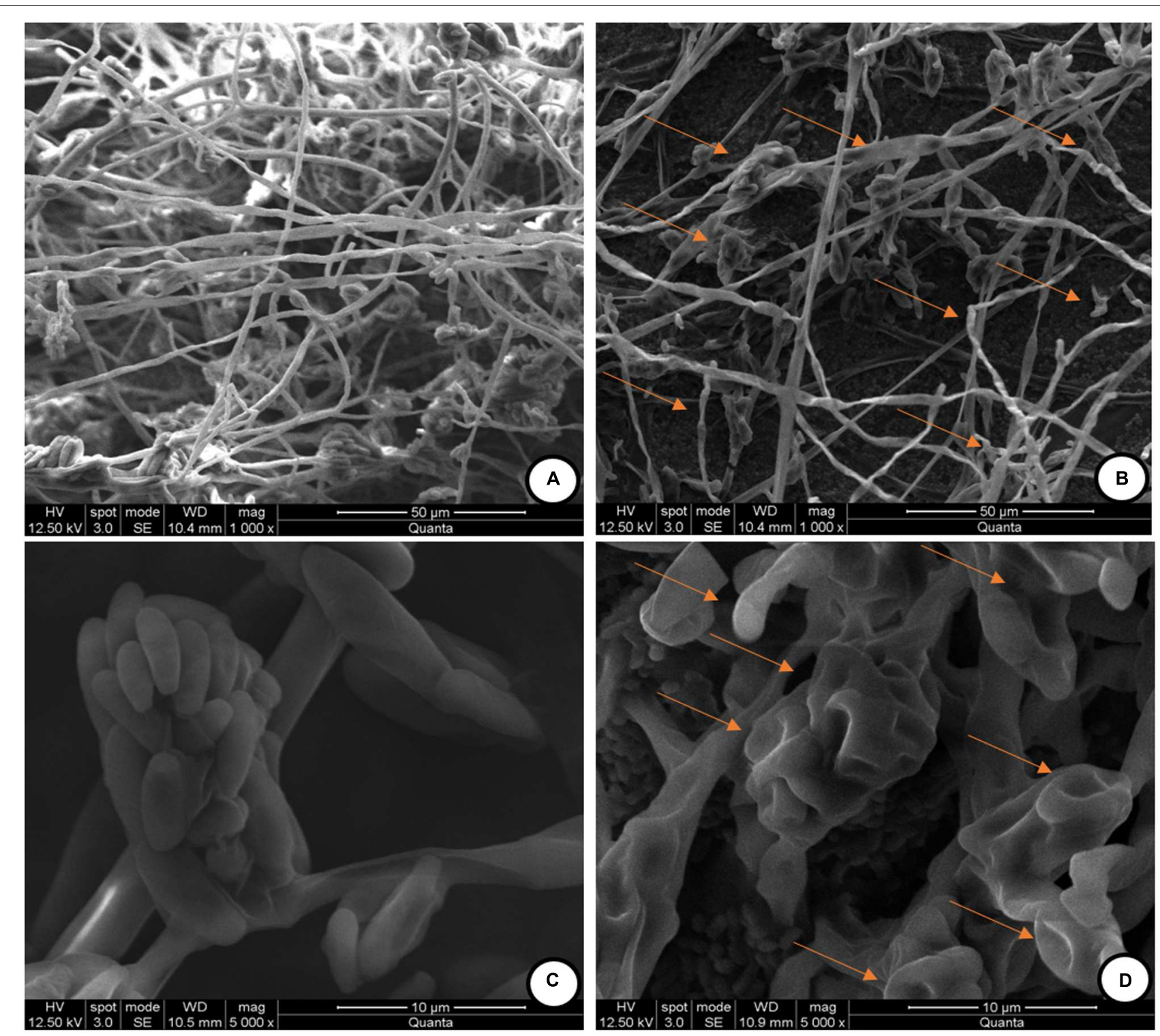

FIGURE 5 | Scanning electron microscopic (SEM) observation of mycelia of $F$. graminearum exposed with $P$. pentosaceus culture supernatant (PPCS). (A) Control mycelia, (C) control spores and, (B,D) were mycelia and spores, respectively treated with minimum inhibitory concentration (MIC) of $P$. pentosaceus culture supernatant (PPCS).

et al. (2015) who studied the morphological effect of B. subtilis SG6 and O. sanctum L. essential oil on mycelia structure of F. graminearum.

Ergosterol is a potent bio-marker for determination of fungal growth (Feng et al., 2005), and in the present study, we determined the effect of PPCS on ergosterol content of F. graminearum. Results evidenced that, PPCS effectively decreased the content of ergosterol in a dosedependent manner as determined by UV- spectrophotometer (Figure 6A). The concentration of ergosterol was quantified by UHPLC, the levels of ergosterol in control was observed as $39.16 \pm 2.91 \mu \mathrm{g}$, whereas in PPCS treated test samples observed with dose-dependent decrease in the concentration of ergosterol, such as $32.71 \pm 2.94 \mu \mathrm{g}$ in $20 \mu \mathrm{L} / \mathrm{mL}$ of PPCS, $23.48 \pm 1.03 \mu \mathrm{g}$ in $40 \mu \mathrm{L} / \mathrm{mL}$ of PPCS and the lowest concentration of $9.34 \pm 1.86 \mu \mathrm{g}$ was recorded at a concentration of $66 \mu \mathrm{L} / \mathrm{mL}$ of PPCS treatment (Figure 6B). Interestingly these results are in agreement with the mechanistic effect of synthetic chemical antifungal agents currently being used for control of fungi, including amphoteric B, miconazole, itraconazole, and clotrimazole. Mode of action of these chemical fungicides, as it binds and creates pores in the membrane, and inhibits the synthesis of ergosterol and in turn leads to the osmotic imbalance, oxidative apoptotic stress and membrane damage (Groll and Kolve, 2004). Therefore, the obtained low ergosterol concentrations in the PPCS 

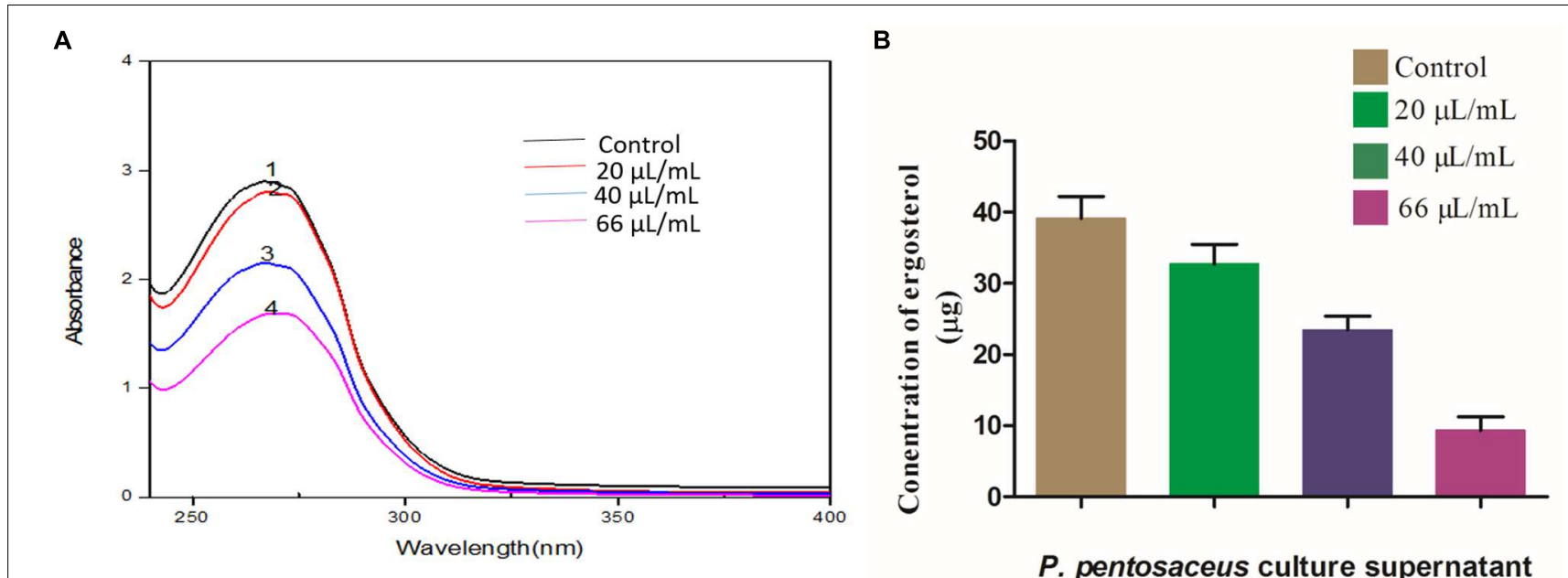

P. pentosaceus culture supernatant

FIGURE 6 | Dose-dependent effects of $P$. pentosaceus culture supernatant (PPCS) on ergosterol biosynthesis of $\boldsymbol{F}$. graminearum determined by (A) UV- spectrophotometry and (B) UHPLC analysis. Data were processed using one-way ANOVA following Tukey's test and $p$ value was significant $(<0.05)$.

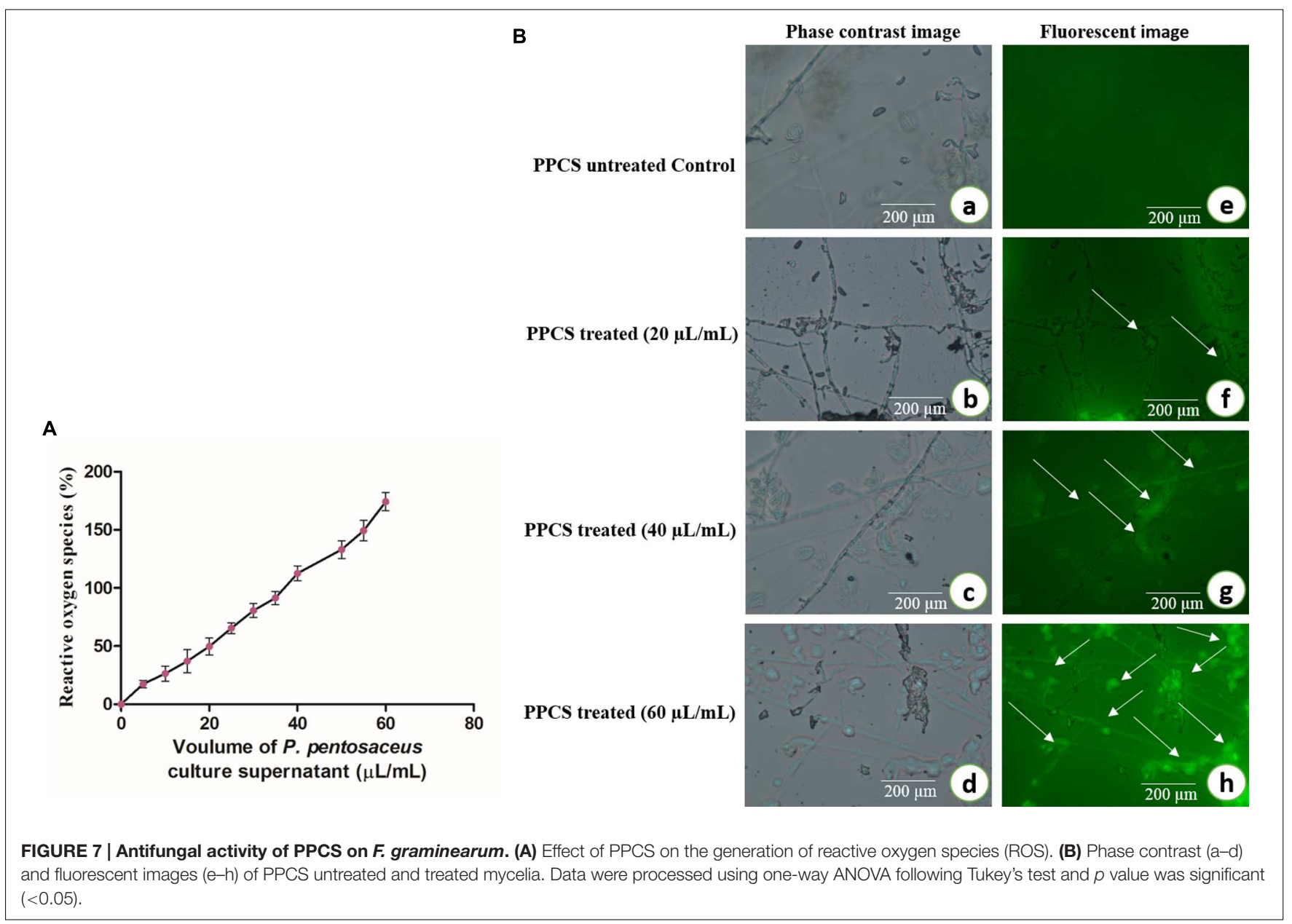

treated samples in the present study strongly support the antifungal activity of PPCS through mitigation of ergosterol metabolism.
Also in another study of ROS, results showed that generation of ROS was increased on increasing concentration of PPCS treatment (Figure 7A). In a biological system, ROS plays an 


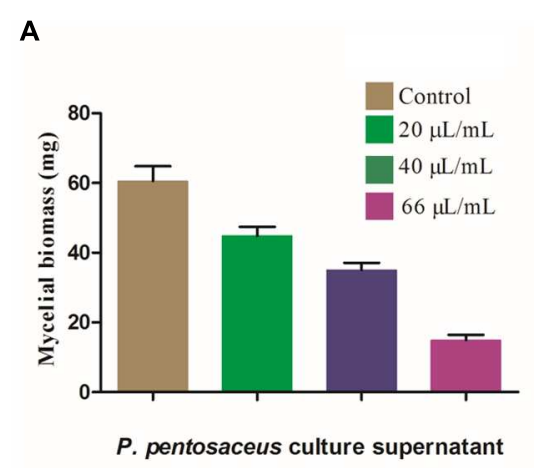

B

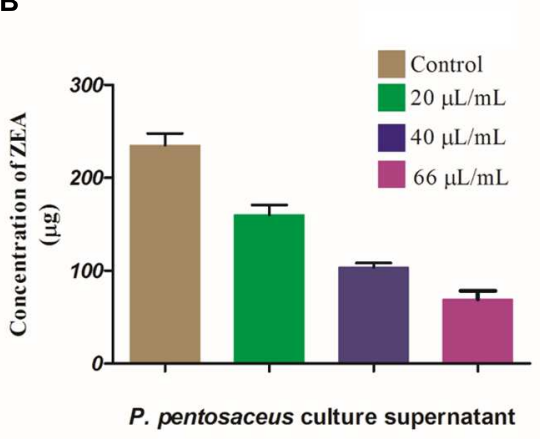

C

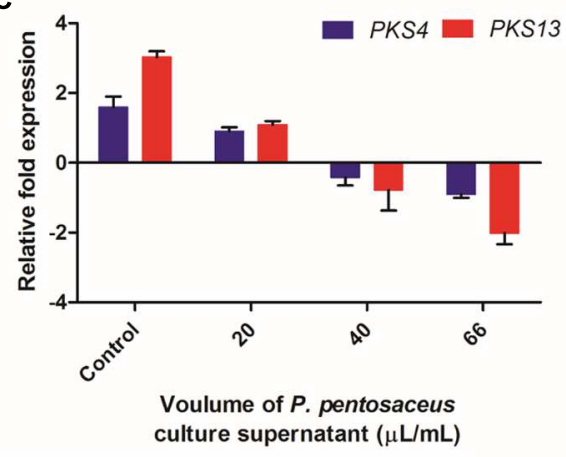

FIGURE 8 | Effect of PPCS on (A) mycelial biomass, (B) zearalenone (ZEA) synthesis, and (C) expression levels of PKS4 and PKS13 (ZEA metabolic genes). Data were processed using one-way ANOVA following Tukey's test and $p$ value was significant $(<0.05)$.

important role in cell signaling and homeostasis, and under stress conditions levels of ROS increases and leads to the damage in the cell membrane, oxidative stress and finally brings apoptosis (Kalagatur et al., 2016). The levels of ROS were observed under a fluorescent microscope and images were observed with higher intensity of fluorescence on increasing concentration of PPCS compared to untreated control (Figure 7B) and this could be also responsible for the antifungal activity of PPCS (Kalagatur et al., 2016).

Also, analysis of ROS clearly suggests that there is the discrete formation of free radicals in PPCS treated mycelium compare with the untreated control (Figure 7). The ROS is the main mechanism involved in oxidative stress thus lead to cause the apoptotic cell death. Recently Kalagatur et al. (2016) also reported the role ROS in the apoptotic mycelial death of F. graminearum.

\section{Antimycotoxic Activity of PPCS}

The main aim of the present study was to evaluate the inhibitory activity of PPCS on ZEA production of $F$. graminearum in broth culture. The effect of PPCS was determined on fungal mycelial biomass, expression of ZEA biosynthetic pathway genes (PKS4 and PKS13) and production of ZEA (Figure 8). Results of the present study revealed that the mycelia biomass at 20, 40, and $66 \mu \mathrm{L} / \mathrm{mL}$ of PPCS treated F. graminearum broth cultures were determined as $44.84 \pm 2.17,35.02 \pm 1.66$, and $14.93 \pm 1.12 \mathrm{mg}$, respectively. Whereas, $60.58 \pm 3.74 \mathrm{mg}$ of mycelia biomass was observed in PPCS untreated control and the mycelial biomass was decreased with increasing the concentration of PPCS (Figure 8A). The concentration of ZEA was quantified by UHPLC analysis and results showed that, ZEA concentration was inversely proportional to the PPCS concentration (Figure $\mathbf{8 B}$ ) and the concentration of ZEA was observed as $235.10 \pm 6.92 \mu \mathrm{g}$ in PPCS untreated control, whereas $160.19 \pm 5.80 \mu \mathrm{g}$ in $20 \mu \mathrm{L} / \mathrm{mL}, 103.65 \pm 2.05 \mu \mathrm{g}$ in $40 \mu \mathrm{L} / \mathrm{mL}$, and $69.12 \pm 5.14 \mu \mathrm{g}$ in $66 \mu \mathrm{L} / \mathrm{mL}$ were recorded in PPCS treated test samples (Figure 8B).

To check the effects of PPCS on ZEA metabolic pathway gene expression and decreased ZEA production in broth culture, we analyzed the target ZEA metabolic pathway genes expression by Rt-qPCR analysis. Results clearly evidenced that, there is a dose-dependent down-regulation of target gene expression when compared to the untreated controls. The down-regulated expression levels of PKS4 and PKS13 were quantified as $0.70 \pm 0.08$ and $1.93 \pm 0.02$ in $20 \mu \mathrm{L} / \mathrm{mL}, 2.05 \pm 0.14$ and $3.81 \pm 1.09$ in $40 \mu \mathrm{L} / \mathrm{mL}, 2.5 \pm 0.06$ and $5.04 \pm 0.80$ in $66 \mu \mathrm{L} / \mathrm{mL}$ of PPCS treated samples, respectively, compared to control (1.60 \pm 0.82 for PKS4 and $3.03 \pm 0.10$ for PKS13) and showed in Figure 8C. Ponts (2015) reported that stress responses including abiotic ( $\mathrm{pH}$, temperature, light, aeration etc.) and biotic (surrounding living organisms) factors cause oxidative burst and as a result fungi release certain secondary chemical metabolites as defense agents called mycotoxins. In our previous study, we demonstrated that antioxidants of $O$. sanctum essential oil were effective in controlling the ZEA synthesis through downregulating the ZEA metabolic pathway genes ( $P K S 4$ and $P K S 13$ ) by Rt-qPCR analysis. In the present study, the observed high antioxidant activity of PPCS was responsible for the decrease in ZEA production through down-regulating PKS4 and PKS13 genes.

\section{CONCLUSION}

Fusarium graminearum cause a severe problem in agriculture and food industry. There is a need for proficient and safe ways to control the growth and mycotoxins of F. graminearum. Our results evidently indicated that, the antifungal potential of P. pentosaceus and its culture supernatant. The PPCS showed the potential inhibitory activity on ZEA production by decreasing the mycelial biomass and down-regulating the ZEA metabolic pathway genes (PKS4 and PKS13). This could be elucidated by the effect of antifungal compounds on the structure and function of nuclear DNA through oxidative nuclear apoptosis mechanisms. Also in the present study, it was observed that, there was a clear lineage among mycelial biomass, target gene expression as well as ZEA production in broth cultures. However, to know the exact mechanism by which PPCS inhibiting the ZEA production by F. graminearum in broth cultures yet to be known. 


\section{AUTHOR CONTRIBUTIONS}

All the authors are equally contributed in the contributed in the present work, including planning and assisted in carrying entire lab work, statistical analysis, and final draft making.

\section{REFERENCES}

Balakrishnan, G., and Agrawal, R. (2014). Antioxidant activity and fatty acid profile of fermented milk prepared by Pediococcus pentosaceus. J. Food Sci. Technol. 51, 4138-4142. doi: 10.1007/s13197-012-0891-9

Bernhoft, A., Torp, M., Clasen, P. E., Løes, A. K., and Kristoffersen, A. B. (2012). Influence of agronomic and climatic factors on Fusarium infestation and mycotoxin contamination of cereals in Norway. Food Addit. Contam. A 29, 1129-1140. doi: 10.1080/19440049.2012.672476

Bondet, V., Brand-Williams, W., and Berset, C. (1997). Kinetics and mechanisms of antioxidant activity using the DPPH free radical method. LWT Food Sci. Technol. 30, 609-615. doi: 10.1006/fstl.1997.0240

Dalie, D. K. D., Deschamps, A. M., Atanasova-Penichon, V., and Richard-Forget, F. (2010). Potential of Pediococcus pentosaceus (L006) isolated from maize leaf to suppress fumonisin-producing fungal growth. J. Food Prot. 73, 1129-1137.

European Commission (2007). Commission regulation (EC) No 1126/2007 of 28 September 2007 amending regulation (EC) No 1881/2006 setting maximum levels for certain contaminants in foodstuffs as regards Fusarium toxins in maize and maize products. Official J. Euro Union L255, 14-17.

Feng, X. M., Eriksson, A. R., and Schnürer, J. (2005). Growth of lactic acid bacteria and Rhizopus oligosporus during barley tempeh fermentation. Int. J. Food Microbiol. 104, 249-256. doi: 10.1016/j.ijfoodmicro.2005.03.005

Fuchs, S., Sontag, G., Stidl, R., Ehrlich, V., Kundi, M., and Knasmüller, S. (2008). Detoxification of patulin and ochratoxin A, two abundant mycotoxins, by lactic acid bacteria. Food Chem. Toxicol. 46, 1398-1407. doi: 10.1016/j.fct.2007.10.008

Gaffoor, I., and Trail, F. (2006). Characterization of two polyketide synthase genes involved in zearalenone biosynthesis in Gibberella zeae. Appl. Environ. Microbiol. 72, 1793-1799. doi: 10.1128/AEM.72.3.1793-1799.2006

Gao, F., Jiang, L. P., Chen, M., Geng, C. Y., Yang, G., Ji, F., et al. (2013). Genotoxic effects induced by zearalenone in a human embryonic kidney cell line. Mutat. Res. 755, 6-10. doi: 10.1016/j.mrgentox.2013.04.009

Gourama, H. (1997). Inhibition of growth and mycotoxin production of Penicillium by Lactobacillus species. LWT Food Sci. Technol. 30, 279-283. doi: 10.4315/0362-028X.JFP-13-360

Gourama, H., and Bullerman, L. B. (1995). Inhibition of growth and aflatoxin production of Aspergillus flavus by Lactobacillus species. J. Food Prot. 58, 1249-1256.

Groll, A. H., and Kolve, H. (2004). Antifungal agents: in vitro susceptibility testing, pharmacodynamics, and prospects for combination therapy. Eur. J. Clin. Microbiol. Infect. Dis. 23, 256-270. doi: 10.1007/s10096-004-1108-6

IARC (1999). Overall evaluations of carcinogenicity to humans. International agency for research on cancer. IARC Monogr. 1-73, 1-36.

JECFA (2000). “Zearalenone," in Safety Evaluation of Certain Food Additives and Contaminants, ed. Joint FAO/WHO Expert Committee on Food Additives (Geneva: WHO/FAO Food additives Series), 393-482.

Kalagatur, N. K., Mudili, V., Anthuvan, A. J., Siddaiah, C., Sreepathi, M. H., and Vardhan, B. H. (2016). Role of Curcuma longa L. essential oil in controlling the growth and zearalenone production of Fusarium graminearum. LWT Food Sci. Technol. 69, 522-528. doi: 10.1016/j.lwt.2016.02.005

Kalagatur, N. K., Mudili, V., Siddaiah, C., Gupta, V. K., Natarajan, G., Sreepathi, M. H., et al. (2015). Antagonistic activity of Ocimum sanctum L. essential oil on growth and zearalenone production by Fusarium graminearum in maize grains. Front. Microbiol. 6:892. doi: 10.3389/fmicb.2015.00892

Kim, Y. T., Lee, Y. R., Jin, J., Han, K. H., Kim, H., Kim, J. C., et al. (2005). Two different polyketide synthase genes are required for synthesis of zearalenone in Gibberella zeae. Mol. Microbiol. 58, 1102-1113. doi: 10.1111/j.13652958.2005.04884.x

Kretschmer, M., Leroch, M., Mosbach, A., Walker, A. S., Fillinger, S., Mernke, D., et al. (2009). Fungicide-driven evolution and molecular basis of multidrug

\section{ACKNOWLEDGMENTS}

Authors are thankful to Dr. Srinivas. M, for his help in the analysis of MALDI-TOF, to Ms. Lakshmi for her support in analyzing the GC-MS and to Mr. Allen for his support in SEM analysis.

resistance in field populations of the grey mould fungus Botrytis cinerea. PLoS Pathog. 5:e1000696. doi: 10.1371/journal.ppat.1000696

Laitila, A., Alakomi, H. L., Raaska, L., Mattila-Sandholm, T., and Haikara, A. (2002). Antifungal activities of two Lactobacillus plantarum strains against Fusarium moulds in vitro and in malting of barley. J. Appl. Microbiol. 93, 566-576. doi: 10.1046/j.1365-2672.2002.01731.x

Lavermicocca, P., Valerio, F., Evidente, A., Lazzaroni, S., Corsetti, A., and Gobbetti, M. (2000). Purification and characterization of novel antifungal compounds from the sourdough Lactobacillus plantarum strain 21B. Appl. Environ. Microbiol. 66, 4084-4090. doi: 10.1128/AEM.66.9.4084-4090.2000

Lavermicocca, P., Valerio, F., and Visconti, A. (2003). Antifungal activity of phenyllactic acid against molds isolated from bakery products. Appl. Environ. Microbiol. 69, 634-640. doi: 10.1128/AEM.69.1.634-640.2003

Magnusson, J., and Schnürer, J. (2001). Lactobacillus coryniformis subsp. coryniformis strain $\mathrm{Si} 3$ produces a broad-spectrum proteinaceous antifungal compound. Appl. Environ. Microbiol. 67, 1-5. doi: 10.1128/AEM.67.1.1-5.2001

Magnusson, M. K., Arvola, A., Hursti, U. K. K., Åberg, L., and Sjödén, P. O. (2003). Choice of organic foods is related to perceived consequences for human health and to environmentally friendly behavior. Appetite 40, 109-117. doi: 10.1016/S0195-6663(03)00002-3

McKellar, R. C., and Lu, X. (eds) (2003). Modeling Microbial Responses in Food. CRC Series in Contemporary Food Science. London: CRC Press.

Minervini, F., and Dell'Aquila, M. E. (2008). Zearalenone and reproductive function in farm animals. Int. J. Mol. Sci. 9, 2570-2584. doi: 10.3390/ijms9122570

Morgavi, D. P., Wiseman, J., and Riley, R. T. (2007). Fusarium and their toxins: mycology, occurrence, toxicity, control and economic impact. Anim. Feed Sci. Technol. 137, 199-374. doi: 10.1016/j.anifeedsci.2007.06.001

Mozzi, F., Raya, R. R., and Vignolo, G. M. (2010). Biotechnology of Lactic acid Bacteria: Novel Applications. Hoboken, NJ: Willey-Blackwell.

Ndagano, D., Lamoureux, T., Dortu, C., Vandermoten, S., and Thonart, P. (2011). Antifungal activity of 2 lactic acid bacteria of the Weissella genus isolated from food. J. Food Sci. 76, M305-M311. doi: 10.1111/j.1750-3841.2011.02257.x

Nishino, T., Shibahara-Sone, H., Kikuchi-Hayakawa, H., and Ishikawa, F. (2000). Transit of radical scavenging activity of milk products prepared by Maillard reaction and Lactobacillus casei strain Shirota fermentation through the hamster intestine. J. Dairy Sci. 83, 915-922. doi: 10.3168/jds.S00220302(00)74954-X

Okcu, G., Ayhan, K., Altuntas, E. G., Vural, N., and Poyrazoglu, E. S. (2016). Determination of phenolic acid decarboxylase produced by lactic acid bacteria isolated from shalgam (şalgam) juice using green analytical chemistry method. LWT Food Sci. Technol. 66, 615-621. doi: 10.1016/j.lwt.2015. 10.072

Peltonen, K., El-Nezami, H., Haskard, C., Ahokas, J., and Salminen, S. (2001). Aflatoxin B 1 binding by dairy strains of lactic acid bacteria and bifidobacteria. J. Dairy Sci. 84, 2152-2156. doi: 10.3168/jds.S0022-0302(01)74660-7

Pitt, J. I., and Hocking, A. D. (2009). Fungi and Food Spoilage, 3rd Edn. New York, NY: Springer, 519.

Pleadin, J., Sokolovic, M., Persi, N., Zadravec, M., Jaki, V., and Vulic, A. (2012). Contamination of maize with deoxynivalenol and zearalenone in Croatia. Food Control 28, 94-98. doi: 10.1016/j.foodcont.2012.04.047

Ponts, N. (2015). Mycotoxins are a component of Fusarium graminearum stressresponse system. Front. Microbiol. 6:1234. doi: 10.3389/fmicb.2015.01234

Priyanka, S. R., Venkataramana, M., Kumar, G. P., Rao, V. K., Murali, H. C. S., and Batra, H. V. (2014). Occurrence and molecular detection of toxigenic Aspergillus species in food grain samples from India. J. Sci. Food Agric. 94, 537-543.

Ramana, M. V., Balakrishna, K., Murali, H. C. S., and Batra, H. V. (2011). Multiplex PCR-based strategy to detect contamination with mycotoxigenic Fusarium 
species in rice and fingermillet collected from southern India. J. Sci. Food Agric. 91, 1666-1673. doi: 10.1002/jsfa.4365

Raut, J. S., and Karuppayil, S. M. (2014). A status review on the medicinal properties of essential oils. Ind. Crop Prod. 62, 250-264. doi: 10.1016/j.indcrop.2014.05.055

Salah-Abbès, J. B., Abbès, S., Abdel-Wahhab, M. A., and Oueslati, R. (2010). Immunotoxicity of zearalenone in Balb/c mice in a high subchronic dosing study counteracted by Raphanus sativus extract. Immunopharmacol. Immunotoxicol. 32, 628-636. doi: 10.3109/08923971003660010

Silva, R. R., Corso, C. R., and Matheus, D. R. (2010). Effect of culture conditions on the biomass determination by ergosterol of Lentinus crinitus and Psilocybe castanella. World J. Microbiol. Biotechnol. 26, 841-846. doi: 10.1007/s11274009-0241-x

Singh, P. K., Sharma, S., Kumari, A., and Korpole, S. (2014). A non-pediocin low molecular weight antimicrobial peptide produced by Pediococcus pentosaceus strain IE-3 shows increased activity under reducing environment. BMC Microbiol. 14:226. doi: 10.1186/s12866-014-0226-2

Stadnik, A., and Borzecki, A. (2009). Influence of the zearalenone on the activity of chosen liver enzymes in a rat. Ann. Agric. Environ. Med. 16, 31-35.

Tellmann, G., and Geulen, O. (2006). LightCycler 480 Real-Time PCR system: innovative solutions for relative quantification. Biochemica 4, 16-18.

Venkataramana, M., Chandranayaka, S., Prakash, H. S., and Niranjana, S. R. (2015). "Mycotoxins relevant to biowarfare and their detection," in Biological Toxins and Bioterrorism (Berlin: Springer), 295-319.

Venkataramana, M., Nayaka, S. C., Anand, T., Rajesh, R., Aiyaz, M., Divakara, S. T., et al. (2014). Zearalenone induced toxicity in SHSY-5Y cells: the role of oxidative stress evidenced by N-acetyl cysteine. Food Chem. Toxicol. 65, 335-342. doi: 10.1016/j.fct.2013.12.042

Venkataramana, M., Shilpa, P., Balakrishna, K., Murali, H. S., and Batra, H. V. (2013). Incidence and multiplex PCR based detection of trichothecene chemotypes of Fusarium culmorum isolates collected from freshly harvested
Maize kernels in Southern India. Braz. J. Microbiol. 44, 401-406. doi: 10.1590/S1517-83822013000200009

Wang, L., Yue, T., Yuan, Y., Wang, Z., Ye, M., and Cai, R. (2015). A new insight into the adsorption mechanism of patulin by the heat-inactive lactic acid bacteria cells. Food Control 50, 104-110. doi: 10.1016/j.foodcont.2014. 08.041

Yoshinari, T., Takeuchi, H., Aoyama, K., Taniguchi, M., Hashiguchi, S., Kai, S., et al. (2014). Occurrence of four Fusarium mycotoxins, deoxynivalenol, zearalenone, T-2 toxin, and HT-2 toxin, in wheat, barley, and Japanese retail food. J. Food Prot. 77, 1940-1946. doi: 10.4315/0362-028X.JFP14-185

Zhao, Y., Selvaraj, J. N., Xing, F., Zhou, L., Wang, Y., Song, H., et al. (2014). Antagonistic action of Bacillus subtilis strain SG6 on Fusarium graminearum. PLoS ONE 9:e92486. doi: 10.1371/journal.pone.00 92486

Zinedine, A., Soriano, J. M., Molto, J. C., and Manes, J. (2007). Review on the toxicity, occurrence, metabolism, detoxification, regulations and intake of zearalenone: an oestrogenic mycotoxins. Food Chem. Toxicol. 45, 1-18. doi: 10.1016/j.fct.2006.07.030

Conflict of Interest Statement: The authors declare that the research was conducted in the absence of any commercial or financial relationships that could be construed as a potential conflict of interest.

Copyright (c) 2016 Sellamani, Kalagatur, Siddaiah, Mudili, Krishna, Natarajan and Rao Putcha. This is an open-access article distributed under the terms of the Creative Commons Attribution License (CC BY). The use, distribution or reproduction in other forums is permitted, provided the original author(s) or licensor are credited and that the original publication in this journal is cited, in accordance with accepted academic practice. No use, distribution or reproduction is permitted which does not comply with these terms. 